\title{
Fostering Technology Stewardship Approach to Promote Knowledge Sharing among Farming Communities in Sri Lanka
}

\author{
H.A.C.K. Jayathilake ${ }^{*}$, U.K. Jayasinghe-Mudalige ${ }^{1}$, L.D.R.D. Perera ${ }^{2}$, \\ G.A. Gow ${ }^{3}$ and N. Waidyanatha ${ }^{4}$ \\ Information Communication Technology Center, \\ Wayamba University of Sri Lanka, \\ Sri Lanka.
}

\begin{abstract}
Agricultural knowledge plays a pivotal role in the process of transforming the livelihoods of farmers relied on subsistence agriculture. However, development of credible approaches to "share" the indigenous and scientific knowledge in possession of farmers in order to enhance their competitive edge in agriculture has become a challenge at present. This paper explores the applicability of theconcept of 'Technology Stewardship' in order to promote sustainable knowledge sharing amongst the agricultural farming communities in Sri Lanka. A community consultative process adopted with the officials ("Sponsors") and a series of structured questionnaire-based face-to-face interviews and keyinformant surveys carried out with a cross section of smallholder agriculture farmers $(n=183)$ in the Batticaloa and Kurunegala districts facilitated gathering of baseline data/information, and in turn, to select and train six Technology Stewards (TEs). A number of field experiments ("Campaigns") were conducted then with smallholder farmers $(n=260)$ "with" and "without" the assistance of those TEs during April 2014 to July 2015. The 'FrontlineSMS' (a low-cost, user-friendly, free and open source text messaging software) and Freedom Fone (low cost Interactive Voice Responses software) were applied to evaluate the effectiveness of knowledge sharing through the TEs work with these communities. It was found that the use of "Texting" and "Voice" facilities in day-to-day agricultural communication has been increased by $22 \%$ and $8 \%$, respectively, when the process has been assisted by the TEs. This implies that TEs can effectively be utilized, with capacity development through intensive training modules, to reduce the transaction costs associated with sharing of information with farmers, starting from the lowest socio-economic category in such communities.
\end{abstract}

Keywords: Agricultural community, Information, Knowledge sharing, Technology stewardship

\section{INTRODUCTION}

Access to agricultural knowledge is key in the process of transforming the livelihoods of rural poor into a one with increased income stability and food security (Lwoga, 2011). Knowledge sharing in support of sustainable agriculture faces numerous challenges at

\footnotetext{
Department of Agribusiness Management, Wayamba University of Sri Lanka

Department of Computing and Information Systems, Wayamba University of Sri Lanka

Faculty of Extension, University of Alberta, Canada

4 LIRNEasia, Sri Lanka

* Corresponding Author: hackjayathilake@gmail.com
} 
present and incorporation of information and communication technologies (ICTs) into agricultural systems could, therefore, be taken as an effective solution to overcome such issues, especially by integrating the local communities in agriculture for collective actions (Aker, 2010).

Shove et al., (2012) and Gow et al., (2013) pointed out that 'free and open source software' (FOSS) platforms can play a greater role in participatory design processes in knowledge sharing approaches. The adoption and use of digital information services as such is, however, closely related to how well these services are aligned with the everyday social practices of people (De Silva et al., 2011; De Silva \& Ratnadiwakara, 2008). We may, therefore, suggest that an existence of such services satisfies a 'necessary' condition, but is not 'sufficient' to foster the development and deployment of new services effectively. The need for "intermediaries" to engage communities in the process of knowledge sharing have, thus, been recognized in these studies. These intermediaries can play the role in part because of their familiarity with the kinds of social practices prevalent within their community. Enrolling the competent 'community knowledge workers' (Grameen Foundation, 2010) or 'technology stewards' can be seen as a solution for this since they can bridge the social practices with technological solutions that are appropriate for the community effectively (Wenger et al., 2009). The role of TEs at work is somewhat similar to that of a "broker" as he/she connects the farmers with an innovative technology so that they can share information amongst them effectively and sustainable manner, and TEs intervention diminishes the transaction costs involved with farmers in term of costs of searching, negotiation and verification of information (De Silva \& Ratnadiwakara, 2008; Jayathilake et al., 2015).

In the context of Sri Lanka, there is an abundance of knowledge on agriculture that has been generated through various sources and institutions (e.g. Universities, Research stations and Departments): These are in very different forms, i.e. printed matter, voiced and/or in cyber space. For example day-to-day communications on prevailing "market prices" and "weather conditions" to reviews and reports that are released periodically. Nevertheless, the smallholder agricultural communities in the country, especially in less-developed rural areas, have persistently been suffered by issues related to receipt of appropriate knowledge and information pertaining to agriculture on time. This has mostly been accrued to the inefficiencies associated with the mode of dissemination (De Silva et al., 2011; Jayathilake et al., 2015).

If the agricultural technologies and developments do not reach farmers in its best form and through the most economical route, transforming sustainable agriculture into productive systems would become an unrealizable effort. Therefore, the relevant agricultural knowledge repositories should come up with new technologies and developments and further attention must be taken to expose them to the potential farmers.

This study examined the potential use of the concept of 'Technology Stewarding' for sustainable knowledge sharing in ICT-enable farming communities in Sri Lanka. Wenger et $a l .$, (2009) points out the significance of incorporating this concept with the ICTs to share the knowledge effectively. This term typically stands for selecting and configuring the relevant technology as well as supporting its use in the practice of the community. The Technology Steward (TE) is a person who works with a community to encourage the adoption and use of digital technologies for communications, training and knowledge transfer. By implementing a technology stewardship program, it will be possible to promote experimentation with digital ICTs, and to build capacity for innovation within a community of practice. Further 
this study explore the current ways of knowledge sharing between agricultural information repositories and smallholder agriculture communities in Sri Lanka.

\section{Materials and Methods}

To practice the technology stewardship (TE) approach, the respective communities and the TEs must be involved actively and enthusiastically in the design process. Therefore, the user centered designs and integrated action research methodologies were adopted throughout the study (Preece et al, 2007). The study was, therefore, planned to be conducted in 5 distinct phases, namely: (1) identifying the sponsors and TEs; (2) Rapid prototyping; (3) designing baseline survey; (4) developing the campaign with iterative testing, and (5) evaluation and designing post campaign survey. The specific activities undertaken in each phase is described, in turn.

\section{Identify the sponsors and technology stewards}

Two institutions working closely with the field level, namely the "Janathakshan" (nongovernmental organization) in Batticaloa and Department of Export Agriculture (DOEA) in Kurunegala, were selected as the 'Sponsors' for this multi-phased study. From these organizations the suitable individuals (Extension officers from DOEA and Technical officers from Janathakshan) were identified for the role of technology stewards for the project. The six TEs identified from the communities were given a comprehensive training on technology stewardship.

Then community consultation process was undertaken with the extension officers, agriculture instructors, deputy directors from these institutions, TEs and farming communities in these districts. Key-informant surveys were used to identify the key issues that they have been faced in terms of knowledge sharing. Community engagement methods and participatory design techniques such as spider diagram, problem tree diagram and use case diagram were used in identifying the key problems. This process has led to furnish quick solutions to such problems by configuring low cost ICTs.

\section{Rapid prototyping exercise}

The above process led to furnish quick solutions to the identified key problems by configuring low cost ICTs and testing the solutions with the community, which is called Rapid Prototyping. TEs play a key role in implementing this practices with ICTs through a process of trial and error with quick turnaround times. Testing and refining a technology platform quickly helps to keep up interest and momentum, reduces costs, and provides immediate feedback on the design of the system in order to improve it for users. FrontlineSMS (text messaging) and Freedom Fone (interactive voice response) were used as its starting point. Fig.1. depicts the general steps followed in rapid prototyping exercise in a community group. 


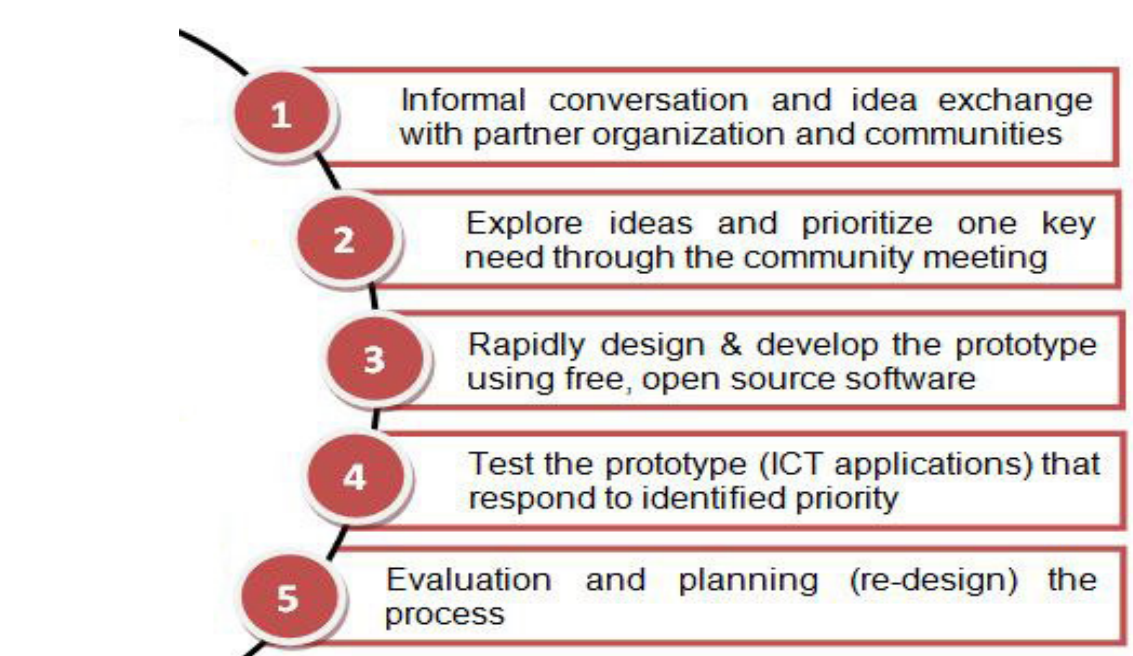

Fig. 1. Steps for Rapid prototyping process in a community group

The FOSS platforms such as FrontlineSMS and Freedom Fone are well suited to rapid prototyping, making it possible to design and test a communication service in real-time with the direct involvement of community participants. This rapid turnaround time makes it possible for participants to immediately experience an implementation, creating the opportunity for direct feedback. It also provides the community with a working beta version of the system (Gow et al., 2013).

\section{Baseline survey}

A series of structured questionnaire-based face-to-face interviews were carried out with a purposively selected sample of smallholder agriculture farmers $(n=183)$ in the same districts to collect baseline information. The 'LIRNEasia Teleuse@BOP4' (LIRNEasia, 2012) instrument was adopted in particularly for the purpose of preparation of questionnaire to gather information pertaining to the socio-economic and demographic data of the respondents as well as their behavior with regard to agriculture information seeking, The survey provided insights as to how, when, and why low cost ICT tools (i.e. mobile phone) were used in their daily lives.

\section{Campaigns}

A campaign is a limited duration activity with a well-defined objective related to the role of ICT and a specific community of practice. TEs assist the community to adopt technology or new technology practices into everyday activities through campaigns. Fig.2. depicts the steps to running a campaign. 


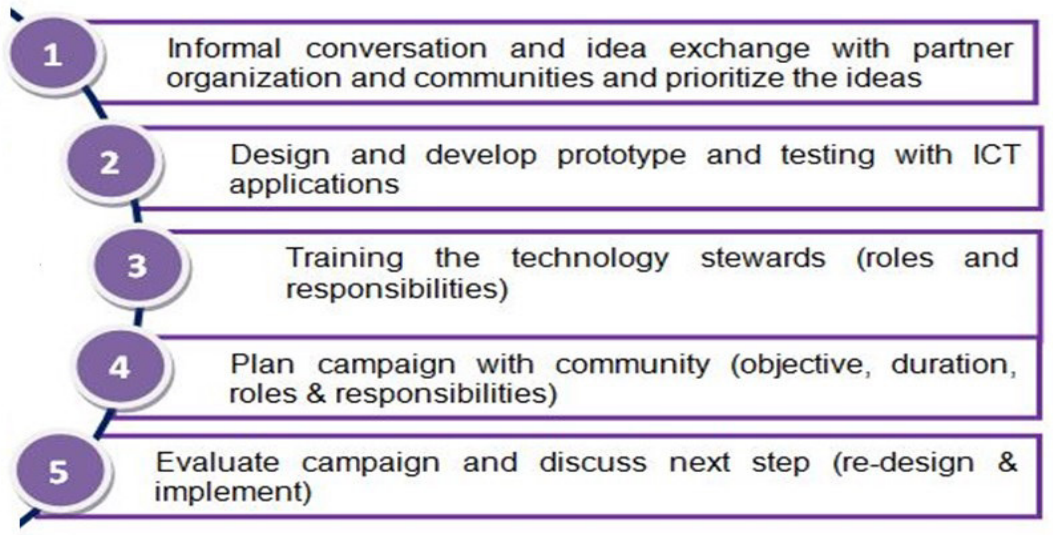

Fig. 2. Steps for running the campaign

Number of field experiments, which were pilot-tested for its accuracy and programmed to run within 3 to 4 months, termed as "Campaigns", were carried out next with 260 smallholder agriculture farmers "with" and "without" the involvement of TEs appointed, where the user-friendly FOSS platforms 'FrontlineSMS' and 'FreedomFone' were adopted. Following Wenger et al. (2009), the evaluative framework for the stewardship model was used in this analysis look into a several factors, including: the involvement and role of the sponsoring organization; the technology steward in promoting the campaign and supporting community members during the campaign, and the level of readiness of the community and its response to the communication campaign as measured by their messaging practices "before" and "after" the campaign.

After the Campaign, another series of face-to-face interviews, supported by a pre-tested structured questionnaire based on 'LIRNEasia Teleuse@BOP4' instrument were carried out with same participants $(\mathrm{n}=183)$, and the "pre" and "post" Campaign survey data and technology usage data from the 'messaging software' deployed in the Campaigns were analyzed. The amount of agriculture related SMS transferred and voice message recorded were used for measuring knowledge sharing. The whole process was carried out during April 2014 to July 2015 for about 15 months uninterruptedly.

\section{Results and Discussions}

Regarding the demographics of participants to the study, 70 percent of farmers participated at this community consultative and baseline data collection process were 'males' and the mean age of a farmer was 48 years. This highlights the participation of women farmers to the process (i.e. 30\%). As a whole, these farmers are in their middle ages that helps grasping those information and communication technologies speedily and effectively. These findings agree with that of Lwoga, (2011), who argues that middle age women farmers acquire ICTs effectively. Further, almost equal number of farmers participated were 'Tamils' (52\%) by nationality and others were 'Sinhalese' (48\%). All the TEs were males and 66 percent of them were Sinhalese and the rest were Tamils by nationality.

When considering the types of agriculture related information that the farming community was expected through an appropriate mode of ICTs, it was found that the majority of farmers 
(90\%) were keen about the 'reliability' of the information with regard to the 'market price' of the crops that they cultivate, Such prices have been fluctuating significantly over time along the value chain and they have no trustworthy source or mechanism to receive such information accurately and on time,. Especially the difference in price between the wholesalers who used to purchase their yield and the consumer markets, as they reside in the places that are far away from the major markets. Further, they want to get clear cut and timely information on 'methods' available and 'materials' that can be used for the purposes of pest and disease control, sustainable crop management, quality seed and plant materials and fertilizer and subsidiary schemes etc., because in their attempt to purchase and use these information they have very often been "misguided" by respective agents, or they are not in position to come up with better deals through negotiation.

It was revealed that farmers used to contact government officers and non-governmental organizations work in the respective area, family members and fellow farmers, farmer organizations and market venders. In fact, a vast majority of farmers $(83 \%)$ have heavily been relied on government officers (i.e. Extension Officer and Regional Development Officer) in the respective area. Farmers used to have regular visits to government offices depending on their needs. It was estimated that such visits were relatively costly for them in terms of travel and subsistence and loss of time.

93 percent of respondents use some mode of phone (during the past 3 months before the survey) to take or receive a telephone call and 68 percent of them used their own mobile phones. This highlights the potential to introduce and utilize ICT enable devices for sharing information, especially through telephony. Especially, the outcome of Kruskal-Wallis test used to assess extent to which the level of knowledge and know-how of farmers effect on this behavior show that the three levels of education used in the analysis (i.e. Grade 0 to $4=$ $35 \%$; Grade 5 to $9=41 \%$; Grade 10 to $12=24 \%$ ) were not statistically significant (chisquare $=20.145, \mathrm{P}=0.1657, \mathrm{df}=2$ ). This implies that farmers, irrespective of their level of education, use mobile phone to share information. Similarly, the two categories used to assess the effect of annual income in this respect (i.e. $<$ Rs. 180,000 per annum $=65 \%$; $>$ Rs. 180,000 per annum $=35 \%$ ) were not statistically significant (chi-square $=36.325, \mathrm{P}=0.1027$, $\mathrm{df}=1$ ) implying that farmers, irrespective of their wealth, use mobile phone to the same extent.

The ICT-enable knowledge sharing Campaign assisted by the Technology Stewards was evaluated with the 'Actor Influenced Matrix' (AIM) which is depicted in Fig.3. In DOEA north campaign, all actors were positively influenced and TEs were very effectively influenced while other campaigns TEs were positively influenced. The outcome of AIM demonstrates that the effectiveness of Technology Stewardship approach was closely associated with the level of influence of the factors examined through the evaluative framework. It was revealed that within this approach, each of these factors, including the Sponsoring organization, the Farming community in concern, and the knowledge, skills, attitudes and mindset of the TE, possess a greater impact on the success of a Campaign. The TE plays a key role to link farmers with the technology. For example, where the community readiness towards accepting an innovation is weak, mainly because of their language skills (since ICT use 'English' terms) and/or other pre-existing conditions the respective TE has to work hard and overtime and invest more resources in the Campaign. 


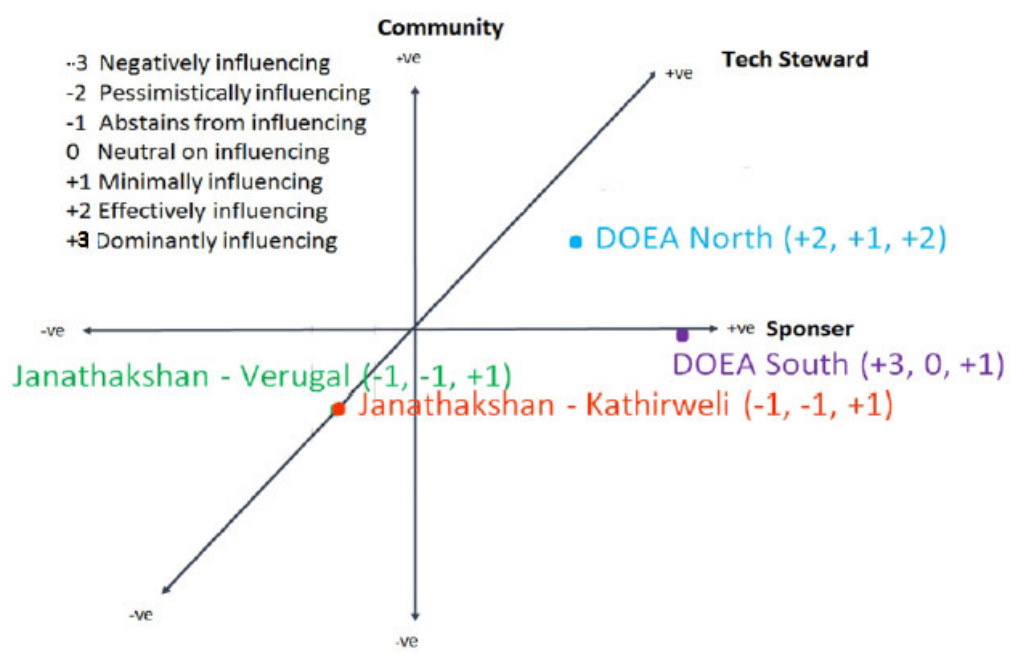

\section{Fig. 3. Actor Influence Matrix (AIM) on campaigns}

Fig.4. summarises the usage of ICT-enable devices for sharing information by these communities with respect to "before" and "after" the campaigns. It shows that technology stewardship intervention (i.e. "with" TEs) increases the use of ICT-enable devices or services, especially 'Text messaging' (SMS) and 'Voice call' usage in day-to-day agricultural communication by 22 and 8 percent, respectively, whereas it was just 5 and 3 percent increase, respectively, for the case of "without" TEs. This highlights the fact that knowledge sharing has increased significantly when the Campaigns were assisted with TEs. Further, the outcome of analysis implies that if the mode of communication one selects for this type of task is "not in the people's existing workflow", the chances of adoption of which by these communities are comparatively low. In fact, this can be taken as the reason as to why 'mobile telephony' (voice \& SMS) has popular and dominant mode of communication within the farming communities.

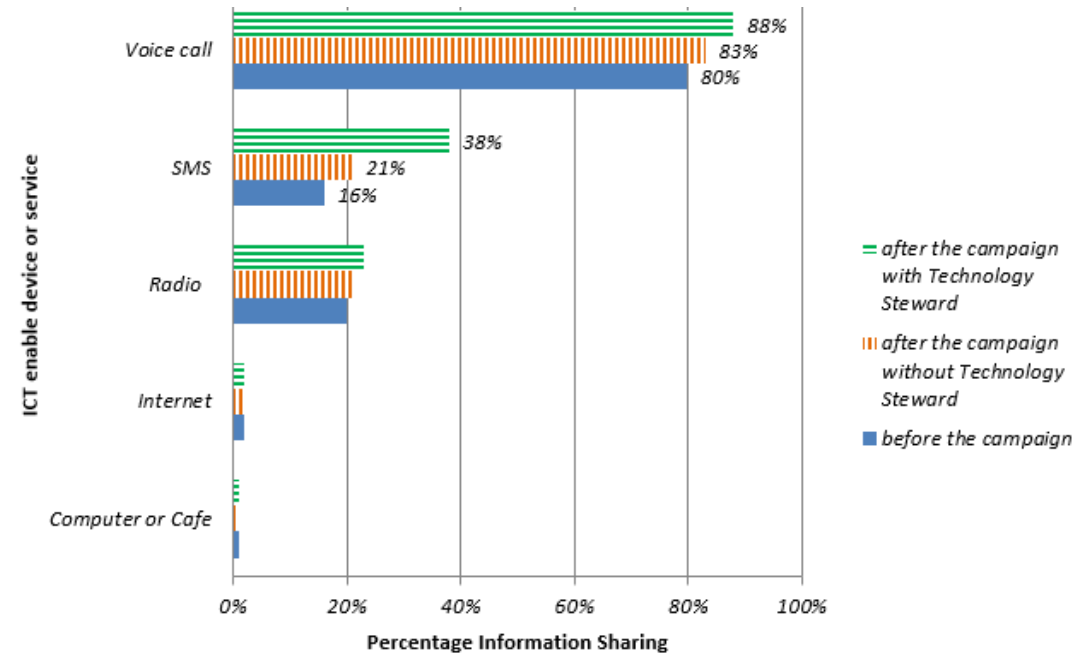

Fig.4. Comparison of the ICT enable devices or services use in information sharing before $\&$ after campaign. 
It was identified that this approach was quite successful as the farmers got the cheap reliable agricultural information of the project through the TEs effort. This intervention led to diminish the transaction costs incurred in the process of knowledge sharing substantially (i.e. searching, negotiation and verification of information). It can be promoted, with necessary modifications like capacity development and introduction of comprehensive training modules for further learning, to work as a drive for positive changes in the livelihood of agriculture-based rural communities. In capacity building process developing and delivering a stewardship curriculum that addresses both technical and community engagement aspects was identified as very important for local innovation with low cost ICTs. Once developed, this approach can play an imperative role in advancing knowledge sharing, starting from the lowest socio-economic category in farming communities.

\section{CONCLUSIONS}

The outcome of this multi-phased research study highlights that the concept of Technology Stewardship introduced to the farming communities in the said districts plays a prominent role to change the way farmers communicate and get solutions to their burning issues in agriculture. Technology stewardship model can be usefully conceived of as a micro-level innovation system. The stakeholders work on these criteria, thus, may come up with appropriate user-friendly packages targeting specific farming communities work on different agricultural products, which shall be regulated by relevant line Ministries working for agriculture to make sure 'right information is shared' and facilitated with various marketbased incentives to 'augment the level of usage'.

The project partnership: Wayamba University of Sri Lanka, University of Alberta and relevant line Ministries working in agriculture is considering the possible benefit of designing a more formal training program for technology stewardship, ICTs familiarization that addresses both technical and community engagement aspects with a view to building community capacity for local innovation with low cost ICTs.

\section{ACKNOWLEDGEMENT}

The authors express their appreciation to the Department of Export Agriculture and Janathakshan for their invaluable contributions made and their ongoing commitment to this project. This project is made possible through the funding from the Social Sciences and Humanities Research Council (SSHRC) of Canada and the Competitive Research Grants Scheme of the Wayamba University of Sri Lanka (SRHDC/RP/04/13-05).

\section{REFERENCES}

Aker, J.C. (2010). Information from Markets Near and Far: Mobile Phones and Agricultural Markets in Niger, American Economic Journal. Applied Economics, 2, 46 59.

Blake, E. and Tucker, W. (2006). Socially Aware Software Engineering for the Developing World, in IST-Africa 2006, P. Cunningham and M. Cunningham, Editors. 2006, IIMC International Management Corporation: Pretoria, South Africa. 
De Silva, H. and Ratnadiwakara, D. (2008). Using ICT to reduce transaction costs in agriculture through better communication: A case-study from Sri Lanka, [online]. [Accessed on 15.01.2015]; Available from http://www.lirneasia.net/wpcontent/uploads/2008/11/transactioncosts.pdf

De Silva, H., Ratnadiwakara, D. and Zainudeen, A. (2011). Social Influence in Mobile Phone Adoption: Evidence from the Bottom of Pyramid in Emerging Asia. Information Technologies and International Development, 7(3), 1 - 18.

Gow, G., Hambly, H., Jayathilake, C, and Waidyanatha, N. (2013). Final Report: 2013 Workshop on Supporting Sustainable Agricultural Communities of Practice with Low Cost ICTs. [Online]. [Accessed on 04.10.2015]; Available from:https://docs.google.com/a/ualberta.ca/file/d/0BwjZ8EhyDFTNSW5xck1BUUhRTjQ/ed it?usp=sharing

Grameen Foundation. (2010). Community Knowledge Worker Pilot Report. 2010 March [online]. [Accessed on 25.10.2015]; Available from: http://www.grameenfoundation.org/resource/community-knowledge-worker-pilot-report.

Jayathilake, H.A.C.K., Jayasinghe-Mudalige, U.K., Gow, G.A., Waidyanatha, N. and Perera, L.D.R.D. (2015). Use of Low Cost Information Communication Technologies for Knowledge Mobilization in Agricultural Communities in Sri Lanka. $8^{\text {th }}$ International Research Conference, General Sir John Kothalawala Defence University, Rathmalana, Sri Lanka

LIRNEasia, (2012). Teleuse at the Bottom of the Pyramid 4 (Teleuse@BOP4) [online]. [Accessed on 01.02.2015]. Available at: http://lirneasia.net/projects/2010-12-researchprogram/teleusebop4

Lwoga, E.T. (2011). Knowledge management approaches in managing agricultural indigenous and exogenous knowledge in Tanzania, Journal of Documentation 67(3), 113 122.

Preece, A. D., Chalmers, S. and McKenzie, C. (2007). A reusable commitment management service using Semantic Web technology. Knowledge-based systems 20(2), 143 - 151

Shove, E., Pantzar, M. and Watson, M. (2012). The dynamics of social practice: Everyday life and how it changes. 2012, London: Sage.

Wenger, E., White, N. and Smith, J.D. (2009). Digital Habitats: Stewarding Technology for Communities. Portland: CPSquare. 